\title{
Spontaneous Subcapsular Hematoma of the Fetal Liver: A Case Report and Review of Literature
}

\author{
James E. Maher, MD ${ }^{1,2}$ Brittany Van Beek, DO² Randall T. Kelly, MD ${ }^{1,2}$ Peter Hsu, MD² \\ ${ }^{1}$ Maternal Fetal Medicine, Medical Center Hospital, Odessa, Texas \\ 2 Department of Obstetrics and Gynecology, Texas Tech University \\ Address for correspondence James E. Maher, MD, Department of \\ Obstetrics and Gynecology, Texas Tech University Health Science \\ Center at the Permian Basin, 701 West 5th Street, Odessa, TX 79763 \\ (e-mail: James.Maher@TTUHSC.edu).
}

Am J Perinatol Rep 2015;5:e203-e206.
Abstract
Keywords
- liver hemangioma
- subcapsular hematoma
- cystic abdominal mass
- prenatal diagnosis

We report a case of a cystic abdominal mass on ultrasound which presented a diagnostic dilemma at 32 weeks gestation. A presumptive antenatal diagnosis of a subcapsular liver hematoma $(\mathrm{SCH})$ was made based on the location and ultrasound appearance similar to $\mathrm{SCH}$ seen in pediatric and adult patients. Sequential evaluation of the mass showed an evolving ultrasound appearance which reinforced our initial impression of a subcapsular hematoma of the fetal liver. Postnatal ultrasound confirmed the resolving $\mathrm{SCH}$ as well as a previously undetected echo bright lesion characteristic of an infantile focal hemangioma directly adjacent to the resolving $\mathrm{SCH}$. A review of the literature is provided.
This 30-year-old gravida-2 para-1 Hispanic female patient presented for care at 9 weeks gestation by dates and ultrasound. The anatomy ultrasound at 20 weeks was unremarkable. She was a smoker with a benign medical and obstetric history. The maternal serum alpha-fetoprotein level was $57.11 \mathrm{ng} / \mathrm{mL}$ (1.09 multiples of median) on second trimester quadruple serum marker screening. Ultrasound examination for growth at 28 weeks was normal.

Follow-up examination at 32 weeks demonstrated the new finding of a cystic right upper quadrant mass in the fetal abdomen measuring $46 \times 27 \times 14 \mathrm{~mm}$ and an otherwise normal examination (-Figs. 1 and 2). The amniotic fluid, movement, tone, posture, muscular activity, and interval growth were noted to be in the normal range. There were no peritoneal calcifications, ascites, hydrops, bowel dilation, or hyperperistalsis. The mass was adjacent to the right lateral border of the liver and moved with diaphragmatic excursion during fetal respirations. Color flow Doppler of the mass showed no high velocity flow. A cystic fibrosis gene probe was obtained and the results were negative for 97 common mutations. Serum TORCH (toxoplasmosis, syphilis, rubella, cytomegalovirus, and herpes infections) studies were negative for signs of recent infection. Fetal echocardiography demonstrated a normal heart without signs of congestive failure or valvular regurgitation.

With advancing gestation, the mass gradually diminished in size and the rim of the lesion became echo bright (-Fig. 3 ). There were complex internal echoes within the cystic lesion consistent with a resolving hematoma.

After consultation with pediatric surgery, labor was induced at 39 weeks gestation. The patient had a spontaneous vaginal delivery of a vigorous female infant with Apgar scores of 8 and 9 at 1 and 5 minutes, respectively, weighing 3,218 g.

Physical examination on the newborn girl revealed no cutaneous hemangiomas, bruising, or petechiae. No palpable liver masses were noted.

Ultrasound evaluation of the neonatal abdomen was performed on the 1st day of life, which demonstrated two adjacent lesions in the periphery of the right lobe of the liver. An oval hypoechoic area with complex internal echoes measuring $7 \times 18 \mathrm{~mm}$ was seen abutting the liver capsule. This lesion was read as a resolving subcapsular hematoma (-Fig. 4). Immediately adjacent and slightly inferior to this lesion was a homogeneous echogenic structure measuring $10 \times 20 \mathrm{~mm}$ with the characteristic ultrasound appearance of a focal infantile hepatic hemangioma ( - Fig. 4). Color flow received

February 1, 2015 accepted after revision June 4, 2015 published online July 24, 2015
DOI http://dx.doi.org/ 10.1055/s-0035-1558403. ISSN 2157-7005.
Copyright (c) 2015 by Thieme Medical Publishers, Inc., 333 Seventh Avenue, New York, NY 10001, USA. Tel: +1(212) 584-4662.
License terms

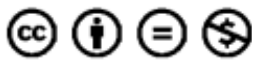




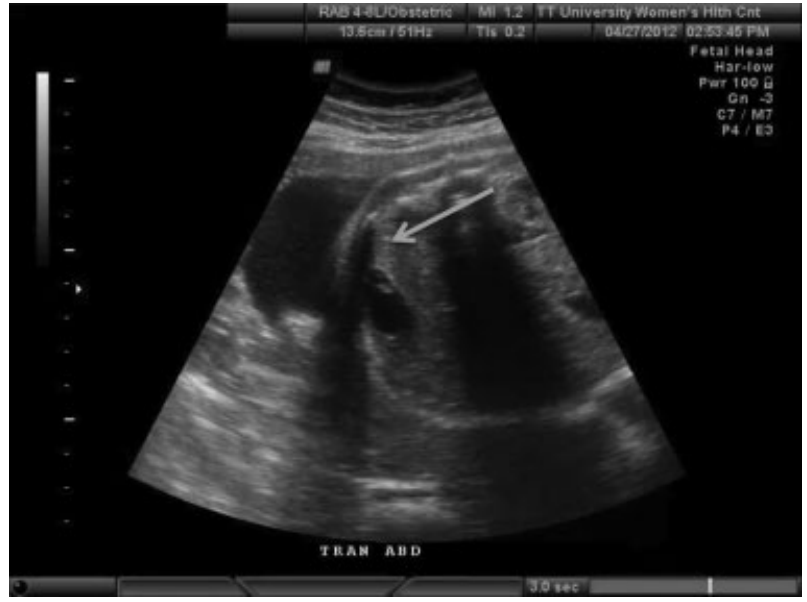

Fig. 1 Transverse fetal abdomen at 32 weeks. The arrow points to the edge of the subcapsular liver hematoma $(\mathrm{SCH})$ on the image.

Doppler evaluation of these areas did not demonstrate highvelocity vascular flow within either lesion ( - Fig. 4). The baby had an unremarkable neonatal course and was discharged home for scheduled follow-up with pediatrician.

\section{Discussion}

We describe an antenatally diagnosed subcapsular liver hematoma ( $\mathrm{SCH}$ ) of the right lobe of the fetal liver which was detected at 32 weeks gestation in an otherwise asymptomatic infant. There were no antenatal risk factors for fetal bleeding diathesis and no evidence of coagulopathy was identified in the neonate. The mother denied any history of antecedent abdominal trauma.

The case presented a diagnostic dilemma. The mass was not associated with bowel dilation, hyperperistalsis, free fluid, or signs suggestive of fetal infection or meconium peritonitis. This mass moved with the liver during fetal respiration and appeared to indent the liver parenchyma. Previously reported

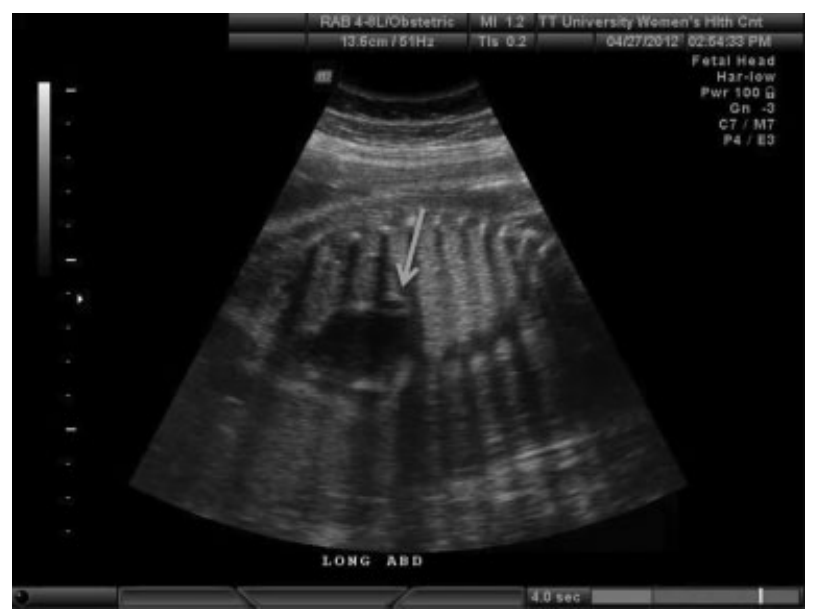

Fig. 2 Sagittal view of cyst at 32 weeks. The arrow points to the edge of the subcapsular liver hematoma $(\mathrm{SCH})$ on the image.

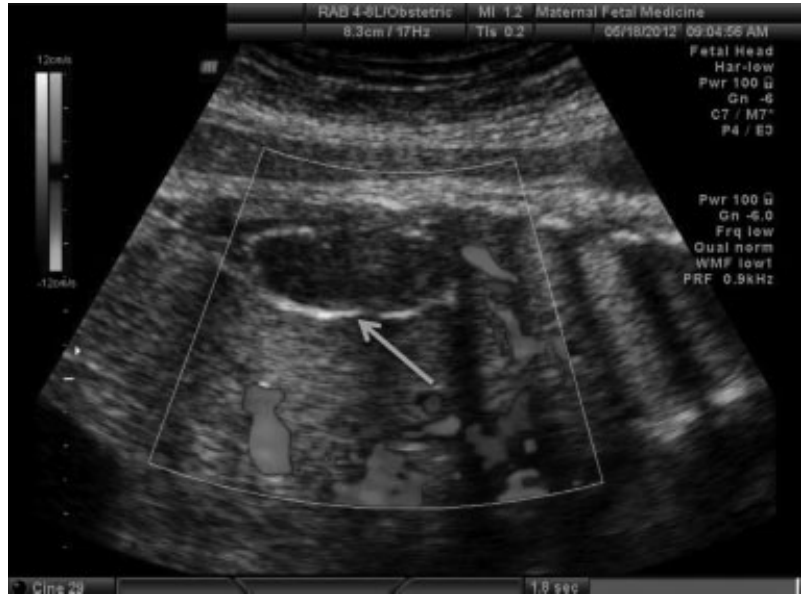

Fig. 3 Sagittal cyst at 35 weeks with color flow. The arrow points to the edge of the subcapsular liver hematoma $(\mathrm{SCH})$ on the image.

causes of fetal cystic hepatic mass include gallbladder duplication, choledochal cysts, nonbile-containing intrahepatic cyst, mesenchymal hamartoma of the liver, ciliated hepatic foregut cyst, and congenital hepatoblastoma. ${ }^{1-9}$

We came to a tentative antenatal diagnosis of SCH based on the location and the ultrasound characteristics of the mass. It was separate from the gallbladder arising just below the dome of the diaphragm and extending down the peritoneal surface of the right lobe of the liver. As the mass evolved it developed an echogenic border and complex internal echoes consistent with an organizing hematoma. Similar ultrasound findings are described in maternal SCH of the liver in association with severe preeclampsia as well as in neonates who developed $\mathrm{SCH}$ of the liver in association with traumatic delivery or umbilical vein catheterization. ${ }^{10,11}$

$\mathrm{SCH}$ of the liver is an infrequent neonatal diagnosis first reported in 1870 by Hodge. ${ }^{12}$ It has been reported at neonatal autopsy in association with severe maternal trauma such as motor vehicle accidents. Other neonatal risk factors for the development of SCH include birth trauma, malpresentation, extreme prematurity, anoxia, sepsis, and a variety of invasive procedures of the neonate. ${ }^{13-15}$ In all of these reports, hematoma of the liver was a postnatal diagnosis.

Comprehensive sonographic evaluation of this fetus revealed no sign of fetal trauma, arteriovenous malformation, anemia, or hepatomegaly. We speculated that the hematoma may have arisen from a vascular malformation or hemangioma in the liver but we were unable to detect a causative lesion before delivery.

Postnatal ultrasound evaluation on the first day of life confirmed the presence of resolving $\mathrm{SCH}$ as well as our suspicion of a causative vascular anomaly, in this case, a focal infantile hepatic hemangioma and we postulate that this hemangioma most likely spontaneously bled in utero during involution, causing the SCH which we detected as a cystic fetal abdominal mass. Even retrospective evaluation of the 


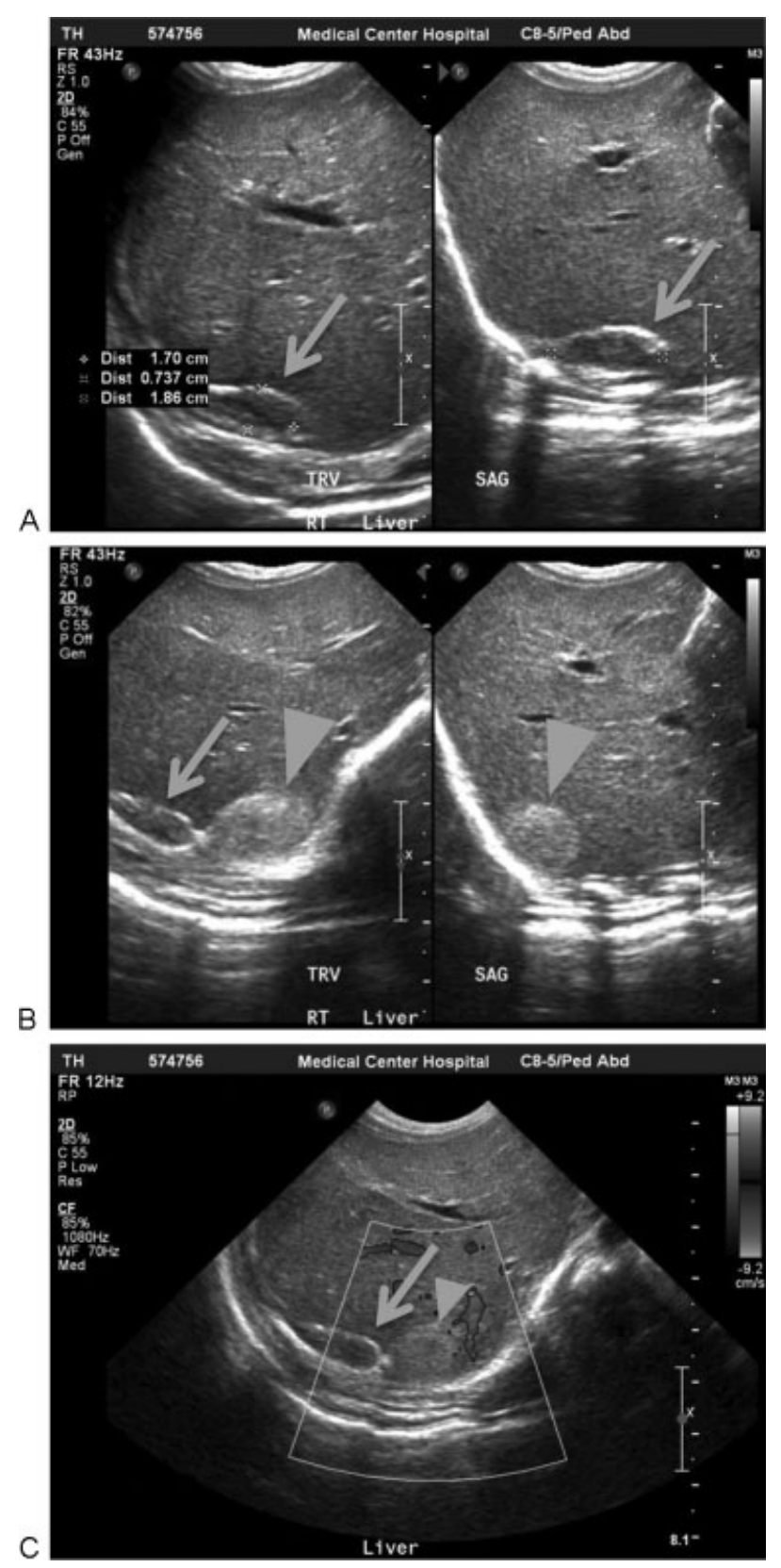

Fig. 4 (A) Postnatal liver ultrasound, resolving subcapsular hematoma. (B) Postnatal liver ultrasound with hemangioma (arrowhead) adjacent to resolving subcapsular hematoma (arrow). (C) Postnatal liver scan with color flow Doppler.

antenatal ultrasound images obtained before and after the cystic fetal abdominal mass was found did not reveal the presence of the adjacent liver hemangioma.

Hepatic hemangiomas are the most common benign tumor of the liver in children. ${ }^{2,3}$ They can range in appearance from solid hyperechoic masses to lesions distorting the surrounding liver and cavernous vascular channels which can lead to congestive failure from the arteriovenous shunting.

Recent attempts in the pediatric surgery literature have been made to standardize and clarify the terminology used to describe infantile hepatic hemangiomas as focal, multifocal, and diffuse hemangiomas. ${ }^{16-19}$ It is hoped that this structure will be useful for reporting as well as developing treatment protocols. The antenatal diagnosis of hepatic hemangiomas has been previously reported ${ }^{1-4,20-25}$ but most of these lesions were discovered during a work-up for hydrops or cardiac decompensation due to high output failure. The most recent summary from the Boston liver hemangioma registry ${ }^{19}$ reported that only focal lesions were detected before birth.

In another recent review article, $28 \%$ of infantile hepatic hemangiomas were diagnosed before delivery and the overall survival for the hemangioma group was $75 \%{ }^{3}$ The causes of death in cases of hepatic hemangioma were fetal hydrops with cardiac failure due to shunting, rupture of the enlarged liver during delivery, and thrombocytopenia resulting from platelet trapping and consumptive coagulopathy (KasabachMerritt) syndrome.

In the neonate, most focal hemangiomas are found during the postnatal evaluation of a palpated abdominal mass or hepatomegaly in an otherwise healthy infant. ${ }^{3}$ Occasionally, focal hemangiomas are found during the work-up of infants with multiple cutaneous hemangiomas. ${ }^{17}$ In most recognized cases, the hemangioma resolves spontaneously without treatment during the first year of life. It is likely that the majority of babies with focal hemangioma of the liver go undetected and unreported. However, there is a report of a lethal outcome in a previously asymptomatic infantile hepatic hemangioma which was detected at autopsy. The child apparently experienced an exsanguinating hemorrhage from involution of a previously unrecognized hemangioma. ${ }^{26}$ It is important to ensure that pediatric follow-up is coordinated, when there is an antenatal diagnosed hepatic lesion, even if they appear to be resolving.

Our case had a unique presentation in that the focal hemangioma most likely spontaneously bled during involution and we detected the resultant fetal SCH on routine antenatal scan. The current case presented a diagnostic challenge in the antenatal evaluation of this evolving cystic intra-abdominal fetal mass and highlights an interesting clinical pathological correlation.

Note

This case report was presented as a poster at the 2014 AIUM National Meeting in Las Vegas and was selected as one of the top 10 posters.

\section{References}

1 Makin E, Davenport M. Fetal and neonatal liver tumours. Early Hum Dev 2010;86(10):637-642

2 von Schweinitz D. Neonatal liver tumours. Semin Neonatol 2003; 8(5):403-410

3 Isaacs H Jr. Fetal and neonatal hepatic tumors. J Pediatr Surg 2007; 42(11):1797-1803

4 Wilson RD. Management of fetal tumors. Best Pract Res Clin Obstet Gynaecol 2008;22(1):159-173

5 Kodandapani S, Pai MV, Kumar V, Pai KV. Prenatal diagnosis of congenital mesenchymal hamartoma of liver: a case report. Case Rep Obstet Gynecol 2011 (e-pub ahead of print). doi: 10.1155/ 2011/932583

6 Charlesworth P, Ade-Ajayi N, Davenport M. Natural history and long-term follow-up of antenatally detected liver cysts. J Pediatr Surg 2007;42(3):494-499 
7 Kinoshita LL, Callen PW, Filly RA, Hill LM. Sonographic detection of gallbladder duplication: two cases discovered in utero. J Ultrasound Med 2002;21(12):1417-1421

8 Martin-Hirsel A, Cantrell CJ, Hulka F. Antenatal diagnosis of a choledochal cyst and annular pancreas. J Ultrasound Med 2004; 23(2):315-318

9 Betalli P, Gobbi D, Talenti E, Alaggio R, Gamba P, Zanon GF. Ciliated hepatic foregut cyst: from antenatal diagnosis to surgery. Pediatr Radiol 2008;38(2):230-232

10 Wicke C, Pereira PL, Neeser E, Flesch I, Rodegerdts EA, Becker HD. Subcapsular liver hematoma in HELLP syndrome: Evaluation of diagnostic and therapeutic options-a unicenter study. Am J Obstet Gynecol 2004;190(1):106-112

11 Lim-Dunham JE, Vade A, Capitano HN, Muraskas J. Characteristic sonographic findings of hepatic erosion by umbilical vein catheters. J Ultrasound Med 2007;26(5):661-666

12 Hodge J. Fatal Hemorrhages from liver in an infant. Am J Med Sci 1870;59:416-421

13 Singer DB, Neave C, Oyer CE, Pinar H. Hepatic subcapsular hematomas in fetuses and neonatal infants. Pediatr Dev Pathol 1999; 2(3):215-220

14 French CE, Waldstein G. Subcapsular hemorrhage of the liver in the newborn. Pediatrics 1982;69(2):204-208

15 Fries MH, Hankins GD. Motor vehicle accident associated with minimal maternal trauma but subsequent fetal demise. Ann Emerg Med 1989;18(3):301-304

16 Buxton PJ, Maheswaran P, Dewbury KC, Moore IE. Neonatal hepatic calcification in subcapsular haematoma with hydrops fetalis. $\mathrm{Br} \mathrm{J}$ Radiol 1991;64(767):1058-1060

17 Dickie B, Dasgupta R, Nair R, et al. Spectrum of hepatic hemangiomas: management and outcome. J Pediatr Surg 2009;44(1):125-133
18 Christison-Lagay ER, Burrows PE, Alomari A, et al. Hepatic hemangiomas: subtype classification and development of a clinical practice algorithm and registry. J Pediatr Surg 2007;42(1): 62-67, discussion 67-68

19 Kulungowski AM, Alomari AI, Chawla A, Christison-Lagay ER, Fishman SJ. Lessons from a liver hemangioma registry: subtype classification. J Pediatr Surg 2012;47(1):165-170

20 Gembruch U, Baschat AA, Gloeckner-Hoffmann K, Gortner L, Germer $\mathrm{U}$. Prenatal diagnosis and management of fetuses with liver hemangiomata. Ultrasound Obstet Gynecol 2002;19(5):454-460

21 Meirowitz NB, Guzman ER, Underberg-Davis SJ, Pellegrino JE, Vintzileos AM. Hepatic hemangioendothelioma: prenatal sonographic findings and evolution of the lesion. J Clin Ultrasound 2000;28(5):258-263

22 Platt LD, Devore GR, Benner P, Siassi B, Ralls PW, Mikity VG. Antenatal diagnosis of a fetal liver mass. J Ultrasound Med 1983;2(11):521-522

23 Morris J, Abbott J, Burrows P, Levine D. Antenatal diagnosis of fetal hepatic hemangioma treated with maternal corticosteroids. Obstet Gynecol 1999;94(5 Pt 2, SUPPL. 1):813-815

24 Mejides AA, Adra AM, O'Sullivan MJ, Nicholas MC. Prenatal diagnosis and therapy for a fetal hepatic vascular malformation. Obstet Gynecol 1995;85(5 Pt 2, SUPPL.):850-853

25 Gonen R, Fong K, Chiasson DA. Prenatal sonographic diagnosis of hepatic hemangioendothelioma with secondary nonimmune hydrops fetalis. Obstet Gynecol 1989;73(3 Pt 2):485-487

26 Dempers J, Wadee SA, Boyd T, Wright C, Odendaal HJ, Sens MA; Prenatal Alcohol and SIDS and Stillbirth (PASS) Network. Hepatic hemangioendothelioma presenting as sudden unexpected death in infancy: a case report. Pediatr Dev Pathol 2011;14(1): 71-74 